\title{
OPEN Dominance style only partially predicts differences in neophobia and social tolerance over food in four macaque species
}

\author{
Federica Amici ${ }^{1,2 \bowtie}$, Anja Widdig ${ }^{1,2}$, Andrew J. J. Maclntosh ${ }^{3}$, Victor Beltrán Francés ${ }^{4}$,
} Alba Castellano-Navarro ${ }^{5}$, Alvaro Lopez Caicoya ${ }^{6}$, Karimullah Karimullah ${ }^{1,7}$, Risma Illa Maulany ${ }^{8}$, Putu Oka Ngakan ${ }^{8}$, Andi Siady Hamzah ${ }^{8}$ \& Bonaventura Majolo ${ }^{9}$

Primates live in complex social systems with social structures ranging from more to less despotic. In less despotic species, dominance might impose fewer constraints on social choices, tolerance is greater than in despotic species and subordinates may have little need to include novel food items in the diet (i.e. neophilia), as contest food competition is lower and resources more equally distributed across group members. Here, we used macaques as a model to assess whether different dominance styles predict differences in neophilia and social tolerance over food. We provided familiar and novel food to 4 groups of wild macaques $(\mathrm{N}=131$ ) with different dominance styles (Macaca fuscata, M. fascicularis, M. sylvanus, M. maura). Our study revealed inter- and intra-specific differences in individuals' access to food, which only partially reflected the dominance styles of the study subjects. Contrary to our prediction, social tolerance over food was higher in more despotic species than in less despotic species. Individuals with a higher dominance rank and being better socially integrated (i.e. higher Eigenvector centrality) were more likely to retrieve food in all species, regardless of their dominance style. Partially in line with our predictions, less integrated individuals more likely overcame neophobia (as compared to more integrated ones), but only in species with more tolerance over food. Our study suggests that individual characteristics (e.g. social integration or personality) other than dominance rank may have a stronger effect on an individual's access to resources.

One of the consequences of group-living is that individuals compete with other group members to attain a dominant position and have preferential access to fitness-related resources. The type and intensity of such within-group competition, and the role of dominance rank in shaping social interactions between group members differ across populations and species. Group-living species display different dominance styles, which vary along a gradient from more to less despotic depending, among other factors, on the symmetry of their agonistic interactions and their conflict management patterns ${ }^{1-4}$. In less despotic species, for instance, aggressive conflicts are expected to have a greater frequency of counter-aggression and more undecided outcomes, higher reconciliation and shallower dominance hierarchies than more despotic species ${ }^{4,5}$. Moreover, dominance might impose fewer constraints on social choices in less despotic species, and individuals might have more opportunities to interact with many different social partners ${ }^{6-11}$.

Although several studies have investigated the relationship between dominance style, aggressive and affiliative behaviour, much less is known about the potential link between dominance style and other important aspects of animal behaviour. Access to resources, for instance, is crucial for all individuals and species, as food provides

${ }^{1}$ Behavioral Ecology Research Group, Institute of Biology, Faculty of Life Science, University of Leipzig, Leipzig, Germany. ${ }^{2}$ Research Group Primate Behavioural Ecology, Department of Human Behavior, Ecology and Culture, Max-Planck Institute for Evolutionary Anthropology, Leipzig, Germany. ${ }^{3}$ Primate Research Institute, Kyoto University, Aichi, Japan. ${ }^{4}$ Fundació Universitat de Girona, Innovació I Formació, Girona, Spain. ${ }^{5}$ Ethology and Animal Welfare Section, Universidad Cardenal Herrera-CEU, CEU Universities, Valencia, Spain. ${ }^{6}$ Department of Clinical Psychology and Psychobiology, Faculty of Psychology, University of Barcelona, Barcelona, Spain. ${ }^{7}$ School of Biological Sciences, Universiti Sains Malaysia, Pulau, Pinang, Malaysia. ${ }^{8}$ Forestry Department, Hasanuddin University, Makassar, Sulawesi, Indonesia. ${ }^{9}$ School of Psychology, University of Lincoln, Lincoln, UK. ${ }^{\boxplus}$ email: amici@eva.mpg.de 
essential energy to live and reproduce ${ }^{12,13}$. Usually, access to food is predicted by individual dominance rank, as higher-ranking individuals usually have priority of access to resources ${ }^{14-20}$. Similarly, access to food may be predicted by an individual integration in the social network, as highly gregarious individuals and/or those individuals connected to highly gregarious partners ${ }^{21}$ might rely on a larger network of social partners and thus experience higher tolerance near food ${ }^{22}$. In less despotic species, however, the importance of rank and social integration in a food acquisition context may be minor compared to despotic species, because subordinates or individuals with weaker social integration may nonetheless receive a higher share of resources, as they may try to access food without a high risk of aggression from more dominant group members ${ }^{23-25}$. Although tolerance over food might be higher in less despotic species $\left(\mathrm{see}^{23-26}\right)$, there are few studies directly comparing access to food sources across species with different dominance styles ${ }^{27,28}$.

Another factor likely to differ depending on the species dominance style is the degree of neophobia, that is, the degree to which individuals avoid novelty ${ }^{29}$. Clearly, no stimulus can be completely novel, as it necessarily shares features (e.g. colour, shape, consistency, odour) with other familiar stimuli that can be generalized to it. In this respect, neophobia should be considered a relative term measuring variation in the response to stimuli of varying familiarity, which we will use here for consistency with previous work. Low levels of neophobia toward novel food, for example, may facilitate exploration and innovation, but they may also expose individuals to novel risks when exploring unfamiliar food ${ }^{30-34}$. Depending on the degree of food competition experienced and on the ease with which they can access food, therefore, individuals may show different levels of neophobia, overcoming their neophobic tendencies when resources are scarce ${ }^{35-42}$. By usually having better access to resources ${ }^{43}$, for instance, higher-ranking individuals may gain lower potential payoffs from novelty, and thus be more neophobic ${ }^{32,44-48}$. Similarly, individuals with better social integration in the group might have higher fitness (see e.g. ${ }^{4-55}$ ), as social integration might favour tolerance and/or support against other competing individuals. Therefore, socially integrated individuals might also obtain lower potential payoffs from novelty $\left(\mathrm{see}^{48}\right)$. If rank and social integration are linked to differences in neophobia, dominance style might play a crucial role to modulate these effects. In more despotic species, food distributions may be less equitable, and less dominant or less integrated individuals may have to more strongly rely on novel, riskier food to survive. To our knowledge, however, no study has directly tested whether different dominance styles affect inter-individual variation in levels of neophobia.

Given these premises, it is clear that comparing species with different dominance styles is necessary to understand whether and how individual differences in neophobia and social tolerance over food are affected by species-specific differences in dominance style, and the role of these differences in modulating the effect of dominance rank and social integration across species. In this study, we used comparative data on four wild populations of macaques to test the link between dominance style, social tolerance and neophobia in a food context. Macaques are well suited for such a comparison, because they are a monophyletic group with a similar social structure, including multi-male multi-female groups, male dispersal and female philopatry, as well as matrilineal dominance hierarchies ${ }^{2,4,5}$. Nonetheless, macaques vary considerably in their dominance style and have been clustered into four grades, from more despotic (grade 1) to less despotic species (grade 4$)^{4,5}$. Therefore, macaques constitute an ideal model for comparative research on sociality, by allowing to test for the effect of dominance style, while indirectly controlling for phylogeny.

We studied four wild groups of macaques, each belonging to a different grade of dominance style: Japanese macaques (Macaca fuscata, grade 1, i.e. highest degree of despotism; hereafter, JM), long-tailed macaques ( $M$. fascicularis, grade 2; LM), Barbary macaques (M. sylvanus, grade 3; BM) and moor macaques (M. maura, grade 4 , i.e. lowest degree of despotism; MM). We used standardized experimental setups by providing food to each study group in different conditions, to test inter- and intra-specific differences in access to food resources. Firstly, given that dominants in more despotic species may better monopolize resources, we predicted that the proportion of individuals having access to food in each session would be higher in less despotic than in more despotic species (Prediction 1). Secondly, we predicted that more dominant and more central individuals (i.e. with stronger connections in the social network ${ }^{21,56}$ ) would likely gain better access to food, but this effect would be stronger in more despotic than in less despotic species (Prediction 2). Finally, we predicted that, in the presence of novel food, the tendency to overcome neophobia would be higher in less dominant and less central individuals (who may otherwise have little access to food), but this effect would be stronger in more despotic than in less despotic species (Prediction 3), as access to food in the former may be more uneven across group members.

\section{Methods}

Ethics. All experimental protocols were approved by the ethics committees of the Kyoto University Wildlife Research Center and the City of Kushima Agency for Cultural Affairs in Japan, by the Kementarian Negara Riset dan Teknologi Republik in Indonesia (RISTEK), and by the Helping Hand Trust in Gibraltar. The study was mainly observational and all study groups were used to occasionally receiving food (see below). No further permits were required. The study was carried out in accordance with the national regulations of all the countries where the study was conducted.

Subjects. We studied four macaque species living in wild populations, selected to represent the four dominance styles described by Thierry ${ }^{4,5}$. We tested one group of 55 Japanese macaques (JM) on Koshima island in Japan, one group of 26 long-tailed macaques (LM) in the Kuala Lumpur district in Malaysia, one group of 20 Barbary macaques (BM) on the cliffs of Gibraltar, and one group of 42 moor macaques (MM) on South Sulawesi in Indonesia. All groups included males and females of different age classes and dominance ranks (see Supplementary Materials and Table S1 for more details on the study animals). In all groups, monkeys exploited natural food, but they were also partially provisioned with small quantities of vegetables and fruit by human tourists (see Supplementary Materials). 


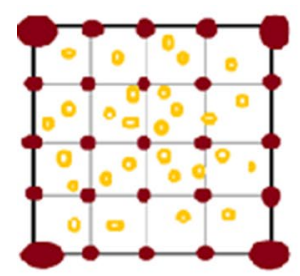

Social tolerance

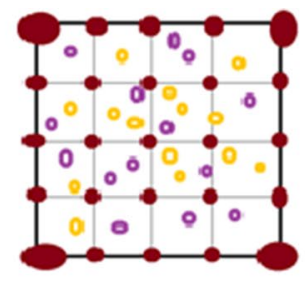

Neophobia (food)

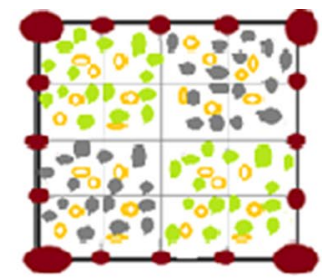

\section{Neophobia (object)}

Figure 1. Set-up of the social tolerance task and the neophobia task (object and food conditions). Yellow circles represent familiar food pieces, and purple circles represent novel food pieces (i.e. dyed food). Green marks represent familiar objects (i.e. natural leaves), and grey marks represent novel objects (i.e. dyed leaf-shaped pieces of salt-dough).

Materials and procedures. We conducted behavioural observations on all the individuals in each group, except for infants (JM: $N=53$; LM: $N=26$; BM: $N=19$; MM: $N=33$ ) during periods when experiments were not administered. For each species, we used the Elo method to assess the dominance hierarchy (EloRating package, version 0.46.11) and obtain the individual scaled Elo-rank (Table S1). Elo-ranks were based on all witnessed dyadic agonistic interactions (see Supplementary Material) with a clear winner-loser outcome (JM: $N=2116$; LM: $N=1627$; BM: $N=126$; MM: $N=346$ ), recorded via all occurrence sampling ${ }^{57,58}$. Dyadic agonistic interactions included aggressive interactions (i.e., bite, chase, threat, lunge), unidirectional agonistic expressions (i.e. open mouth, displacement) and unidirectional submissive behaviours (i.e. make room, bared-teeth display). The individual start values and the $\mathrm{k}$ factor (a weighted constant based on the probability of winning) were set by default at 1000 and 100, respectively. We then averaged the values obtained through the study periods, standardizing them to range from 0 to 1 (i.e. 0 being the lowest and 1 the highest rank). Below, we refer to these values as Elo-ranks. Elo-ranks were very stable through the study period, so we included no burn in periods. We assessed rank stability using the stab_elo function and visually inspecting the Elo-ranks $\left(\mathrm{see}^{58}\right)$. The Elo-ranks were very stable in all study groups (JM: 0.988; LM: 0.989; BM: 0.992; MM: 0.988).

Furthermore, we assessed the spatial proximity network for each study group, based on data collected with instantaneous scans made once an hour, recording the spatially closest individual ("nearest neighbour") of each group member. We then built an undirected weighted matrix and ran social network analyses with the following R packages: vegan (version $2.5-3^{59}$ ), asnipe (version $1.1 .10^{60}$ ), and igraph (version $1.2 .1^{61}$ ). We further used social network analyses to measure individuals' Eigenvector centrality (Table S1), which is proportional to the sum of the centralities of an individual's neighbours and assesses the importance of individuals as social hubs ${ }^{21,56}$. Individual Eigenvector centrality scores ranged from 0 to 1 . We recorded $199 \mathrm{~h}$ of scan data in JM, $139 \mathrm{~h}$ in LM, $61 \mathrm{~h}$ in BM, and $229 \mathrm{~h}$ in MM. The lower number of observations hours for BM is due to the fact that the study group lived on a cliff, and could not be followed as much as the other groups.

During the study period, on designated days each group was administered a social tolerance task, followed by a neophobia task. In both tasks, animals were tested in a testing arena, which consisted of a $4 \mathrm{~m} \times 4 \mathrm{~m}$ square area, divided into 4 identical $1 \mathrm{~m} \times 1 \mathrm{~m}$ squares marked with stones or branches taken from the local natural environment (Fig. 1). The testing arena was set up in a flat area with little to no vegetation (so that the testing arena was clearly visible), but where the groups naturally foraged on a daily basis.

In the social tolerance task (Fig. 1), subjects were administered 60 sessions per species. Although we aimed to administer 10 sessions a day per group, this was not always possible (i.e., when monkeys left the testing arena to forage in other areas), so the number of testing days varied across groups (JM: 6 days; LM and BM: 7 days each; MM: 9 days). When the group was within view (i.e. more than half of the group members were present), the experimenter threw preferred food items in the testing arena. The session started when the first monkey entered the testing arena. Food consisted of banana slices for all groups, except for JM, who were tested with slices of sweet potato due to dietary restrictions at Koshima. To ensure that this difference had no effect on our results, we re-ran our analyses (see below) after removing JM from the data-set. Results were similar, confirming the significant effect of the same predictors (see Supplementary Materials). Food was distributed evenly throughout the testing arena, and was proportional to the number of adult individuals in each group (i.e., number of adults in the group $\times 0.4$, rounded to the closest even number). However, the number of food pieces retrieved by the macaques did not always coincide with the number of food pieces distributed in the testing arena by the experimenter, either because some pieces were not retrieved (e.g. if they inadvertently got covered) or because some pieces were taken by several individuals (e.g. the pieces were dropped and broken, so that more individuals sampled the original piece). The trial ended when the last piece of food was eaten, if no monkey was in the testing arena for more than $30 \mathrm{~s}$, or if no monkey retrieved food from the testing arena for more than $30 \mathrm{~s}$. At the end of each session, the testing arena was cleaned and new food was distributed throughout, with an interval of at least 5 min between sessions. All group members participated in at least one session of the task.

In the neophobia task, we administered two different conditions (i.e., food and object conditions), to assess reactions to novelty in two different contexts (Fig. 1). The procedure was identical to the social tolerance task, with the following exceptions. In the food condition, half of the food pieces had previously been dyed with a 
novel food-colour (i.e., red in half of the sessions, and blue in the other half, to maintain novelty high), having no odour and no taste. In the object condition, we first distributed local leaves familiar to the monkeys in two nonadjacent $2 \times 2-\mathrm{m}$ squares of the testing arena, and novel coloured pieces of salt-dough in the other two squares. These novel objects had a leaf-shape and size, but clearly differed from a leaf, by having a clay-consistency and being painted in bright colours (i.e. silver in half of the sessions, and another colour in the other half, the second colour differing across species to ensure that the novel objects did not have the same colour of the real leaves, e.g. because of the season). Then, we distributed food as in the social tolerance task. In this way, we could simultaneously present both novel and familiar stimuli to the study subjects, and thus obtain a more controlled measure of neophobia, by measuring the number of familiar versus novel food items retrieved by each individual in each session (see below). We administered 40 sessions per species and condition, starting with 20 food sessions followed by 20 object sessions, and then 20 further food sessions followed by 20 object sessions (using different colours). We used two different conditions, and two different stimuli per condition to create more accurate measures of novelty response ${ }^{62}$, and short sessions to avoid habituation to the novel stimuli ${ }^{29}$.

All sessions were video-recorded. During each session, the experimenter named each individual entering the testing arena, so that it was later possible to code from the videos: (i) which individual entered the testing arena in each session, (ii) how many food pieces were eaten by each individual per session, and (iii) whether the food retrieved was familiar/novel (in the food condition) or collected in the squares with familiar/novel objects (in the object condition).

Statistical analyses. To avoid the usual top-down approach to the study of dominance styles (i.e. using pre-determined classifications of dominance style for the study species), we directly assessed the dominance styles of the study groups by measuring the steepness of their dominance hierarchy ${ }^{63}$. We used the package steepness (version $0.2-2 ;^{64}$ ) in $\mathrm{R}^{65}$ to assess the steepness of the hierarchy in each species, which is considered a central measure of dominance style $e^{4,58}$. Steepness was calculated as the absolute value of the slope straight line fitted to the normalized David's scores, calculated from the proportions of wins in dyadic agonistic interactions ${ }^{63}$. This is considered a more appropriate measure when overall observation time varies between study groups, and actors and recipients interact consistently but infrequently, and is expected to be higher in more despotic species ${ }^{66}$. However, steepness might decrease when the proportion of unknown relationships in a group increases ${ }^{67}$. As the proportion of unknown relationships differed across species (i.e. JM: 51\%; LM: 49\%; BM: 57\%; MM: 62\%), we randomly removed dyads with known relationship from the JM, LM and BM dominance matrices, until we reached the same proportion of unknown relationships across all species (i.e. 62\%). We then averaged the values obtained over 1000 iterations, and finally assessed the adjusted steepness of the dominance hierarchy for all study species (hereafter, steepness; see $^{67}$ ).

We then constructed generalized linear models (GLMs) and generalized linear mixed models (GLMMs ${ }^{68}$ ) with the glmmTMB package (version $1.0 .1^{69}$ ) in $\mathrm{R}^{65}$ to analyse our data. First, we tested whether the proportion of individuals retrieving food was higher in less despotic species (Prediction 1). To test this prediction, we used a binomial GLM to assess whether the relative number of individuals retrieving food in each session of the social tolerance task (versus the number of those retrieving no food, using the 'cbind' function) was predicted by the steepness of the species, while controlling for session number (model 1). As we entered one line per session and species, each data point was an independent observation, and no random factors were included.

Second, we tested whether dominance rank and Eigenvector centrality differently affected the probability to retrieve food, depending on the species' dominance styles (Prediction 2). To test this prediction, we ran a binomial GLMM with the relative number of food pieces retrieved by each subject in each session of the social tolerance task (versus the number of food pieces not retrieved, using the 'cbind' function in $\mathrm{R}^{65}$ ) as the dependent variable. In the full model, we included as test predictors the 2-way interactions of steepness with rank and steepness with Eigenvector centrality, along with their main effects. We further included age class, sex and session number as control predictors, and subject identity as a random factor (model 2).

Finally, we tested whether rank and Eigenvector centrality differently affected neophobia (i.e. the probability to retrieve familiar rather than novel food), depending on the species dominance styles (Prediction 3). Accordingly, we used a binomial GLMM to assess whether the relative number of familiar versus novel food items retrieved by each individual in each session of the neophobia task (using the 'cbind' function) was affected by the 2 -way interactions of steepness with rank and steepness with Eigenvector centrality, along with their main effects. We further included sex, age class, session number and condition (i.e., novel food or novel object) as control predictors, and subject identity as random factor (model 3 ).

We used likelihood ratio tests ${ }^{70}$ to compare full models containing test, control predictors and random factors, with null models containing only control predictors and random factors using the anova function. If full models were significantly different from null models, we conducted likelihood ratio tests ad used the R function drop $1^{71}$ to obtain the $p$ values for each test predictor via single-term deletion. If the 2 -way interactions were not significant, we ran the full model again, after removing the interaction and only leaving the main effects. To rule out collinearity, we assessed the VIFs ${ }^{72}$, which were low (maximum VIFs across all models $=1.86$ ). This indicated no collinearity between our test predictors. We detected no convergence issues in any of the models.

\section{Results}

The steepness of the dominance hierarchy varied across species largely in line with what was predicted from literature (steepness: JM: 0.280; LM: 0.290; BM: 0.244; MM: 0.163; adjusted steepness: JM: 0.255; LM: 0.259; BM: 0.234; MM: 0.163). As expected, the least despotic species, MM, had the lowest steepness. However, the difference in steepness for the other three species were less pronounced. Steepness was unexpectedly higher in LM than in JM, but only slightly so. 


\begin{tabular}{|c|c|c|c|c|c|c|c|c|}
\hline Model 1 & Estimate & SE & $z$ & $2.5 \% \mathrm{CI}$ & $97.5 \% \mathrm{CI}$ & LRT & $d f$ & $P$ \\
\hline Intercept & -3.13 & 0.22 & -14.79 & -3.75 & -2.87 & - & - & - \\
\hline Steepness & 6.54 & 0.91 & 7.21 & 4.76 & 8.32 & 56.75 & 1 & $<0.001^{*}$ \\
\hline Session & 0.00 & 0.00 & 0.66 & 0.00 & 0.00 & 0.43 & 1 & 0.510 \\
\hline Model 2 & Estimate & SE & $z$ & $2.5 \% \mathrm{CI}$ & $97.5 \% \mathrm{CI}$ & LRT & $d f$ & $P$ \\
\hline Intercept & -9.29 & 1.00 & -9.32 & -11.23 & -7.33 & - & - & - \\
\hline Steepness & -6.56 & 4.07 & -1.61 & -14.55 & 1.43 & 2.57 & 1 & 0.109 \\
\hline Rank & 4.83 & 1.06 & 4.53 & 2.74 & 6.91 & 19.38 & 1 & $<0.001^{*}$ \\
\hline Centrality & 6.11 & 0.69 & 8.81 & 4.75 & 7.47 & 73.16 & 1 & $<0.001^{\star}$ \\
\hline Age (Juvenile) & 0.24 & 0.48 & 0.49 & -0.70 & 1.17 & \multirow{2}{*}{0.27} & \multirow{2}{*}{2} & \multirow{2}{*}{0.875} \\
\hline Age (Subadult) & 0.16 & 0.49 & 0.33 & -0.80 & 1.11 & & & \\
\hline Sex (Male) & 0.50 & 0.35 & 1.42 & -0.19 & 1.20 & 2.00 & 1 & 0.158 \\
\hline Session & 0.00 & 0.00 & 0.16 & 0.00 & 0.00 & 0.03 & 1 & 0.871 \\
\hline Model 3 & Estimate & SE & $z$ & $2.5 \% \mathrm{CI}$ & $97.5 \% \mathrm{CI}$ & LRT & $d f$ & $P$ \\
\hline Intercept & -1.30 & 1.20 & -1.09 & $-3 / 65$ & 1.05 & - & - & - \\
\hline Steepness * centrality & -17.86 & 8.63 & -2.07 & -34.77 & -0.95 & 4.20 & 1 & $0.040^{*}$ \\
\hline Steepness & 4.66 & 5.29 & 0.88 & -5.72 & 15.03 & - & - & - \\
\hline Centrality & 4.52 & 2.09 & 2.16 & 0.42 & 8.62 & - & - & - \\
\hline Rank & 0.24 & 0.41 & 0.58 & -0.57 & 1.05 & 0.34 & 1 & 0.560 \\
\hline Condition & -0.66 & 0.06 & -11.03 & -0.78 & -0.54 & 123.62 & 1 & $<0.001$ \\
\hline Age (Juvenile) & 0.02 & 0.19 & 0.10 & -0.35 & 0.39 & \multirow{2}{*}{1.35} & \multirow{2}{*}{2} & \multirow{2}{*}{0.509} \\
\hline Age (Subadult) & 0.20 & 0.18 & 1.08 & -0.16 & 0.55 & & & \\
\hline Sex (Male) & 0.08 & 0.14 & 0.55 & -0.19 & 0.35 & 0.30 & 1 & 0.582 \\
\hline Session & 0.00 & 0.00 & -0.75 & 0.00 & 0.00 & 0.56 & 1 & 0.453 \\
\hline
\end{tabular}

Table 1. Results of models 1 to 3, including estimates, standard errors (SE), z-values ( $z$ ), confidence intervals (CIs), likelihood ratio tests (LRT), degrees of freedom (df), and $P$ values for each test and control predictor (in parentheses, the reference category). Subject identity was included as a random factor in models 2 and 3 . The asterisks denote significant $p$ values for the test predictors. Control predictors are in italics.

The proportion of individuals retrieving food in each session was highest in LM $(0.36 \pm 0.19)$, and lowest in $\mathrm{JM}(0.08 \pm 0.04)$, with $\mathrm{BM}$ and MM showing intermediate levels $(0.12 \pm 0.05$ and $0.11 \pm 0.04$, respectively). In model 1, we tested whether the proportion of individuals retrieving food was higher in less despotic species (Prediction 1). The full model significantly differed from the null model (GLM: $\left.\chi^{2}=56.75, \mathrm{df}=1, p<0.001\right)$, with a higher steepness predicting a higher proportion of individuals retrieving food ( $p<0.001$; Table 1; Fig. 2).

In model 2, we tested whether dominance rank and Eigenvector centrality differently affected the probability to retrieve food, depending on the species dominance styles (Prediction 2). The full-null model comparison was significant (GLMM: $\chi^{2}=118.46, \mathrm{df}=5, p<0.001$ ), but none of the 2 -way interactions were. However, a higher rank and higher Eigenvector centrality both predicted a higher proportion of food retrieved, in all species (both $p<0.001$; Table 1; Fig. 3a,b).

In model 3, we finally tested whether rank and Eigenvector centrality differently affected neophobia, depending on the species dominance style (Prediction 3). The full-null model comparison was significant (GLMM: $\chi^{2}=23.16, \mathrm{df}=8, p=0.003$ ). We also found a significant 2 -way interaction between steepness and Eigenvector centrality ( $p=0.031$; Table 1$)$ : less central individuals were less neophobic (i.e. they were less likely to consume a higher proportion of familiar food), but only in species with lower steepness (Fig. 4).

\section{Discussion}

In this study, we found that different dominance styles ${ }^{4,5}$ only partially predicted the way in which food resources were divided across group members. Firstly, the proportion of individuals accessing food in each session was higher in more despotic species (i.e. with higher dominance steepness), in contrast with our Prediction 1. Secondly, more dominant and more central (i.e. socially integrated) individuals had a higher probability of retrieving food, but this effect was similarly strong in all species, regardless of their dominance steepness (only partially in line with Prediction 2). Finally, less central individuals (who may otherwise have little access to food) were more likely to overcome neophobia than central ones (partially in line with Prediction 3), but only in more despotic species (in contrast with Prediction 3).

Our results suggest that dominance styles have an unexpected effect on how food resources are distributed across group members. In less despotic species, individuals had a lower share of resources (Model 1), and individuals with higher rank and Eigenvector centrality were more likely to retrieve food, similarly to what was found in more despotic species (Model 2). Less despotic species may have less intense aggressive patterns ${ }^{3,4,8}$, but not higher tolerance over food. Alternatively, inter-specific differences in dominance styles may imply a higher intra-specific variation than previously thought, with different aspects of dominance style (e.g. steepness of the dominance hierarchy, occurrence of counter-aggression, tolerance over food) also varying across conspecific 


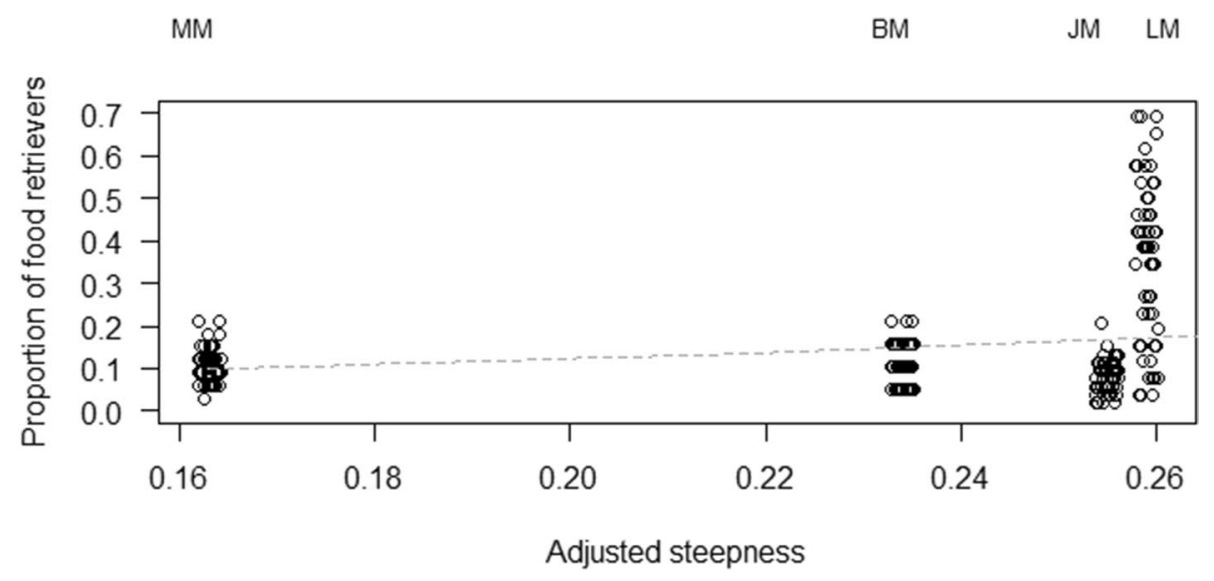

Figure 2. Mean proportion of food retrievers in the social tolerance task, as a function of the steepness of the species (see model 1). Circles represent sessions and are jittered to avoid overlap. The dashed line depicts the model, which has been back-transformed from the log-odds ratio scale and contains standardized controls.
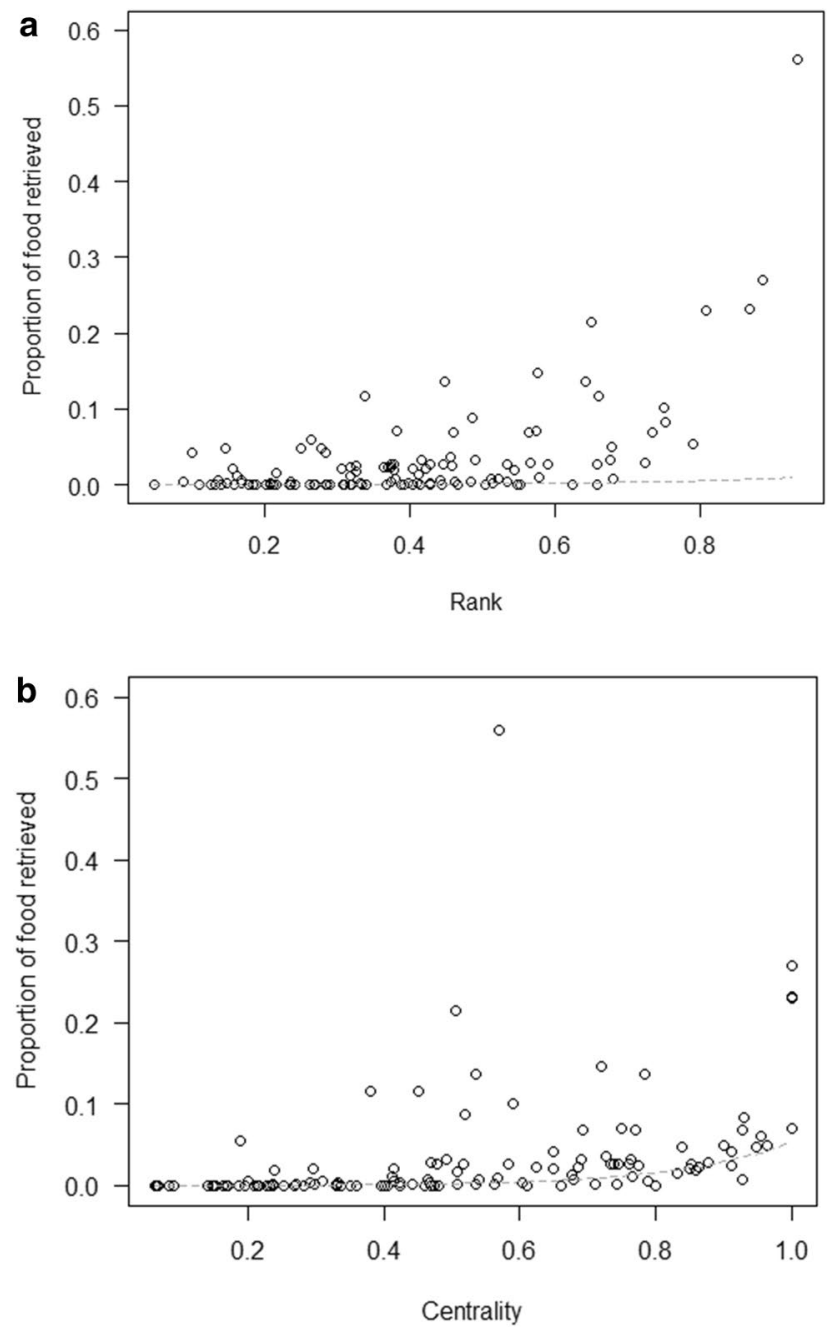

Figure 3. Mean proportion of food retrieved by the study subjects in the social tolerance task, as a function of their (a) rank and (b) Eigenvector centrality (see model 2). Circles represent the study subjects and are jittered to avoid overlap. The dashed line depicts the model, which has been back-transformed from the log-odds ratio scale and contains standardized controls. 


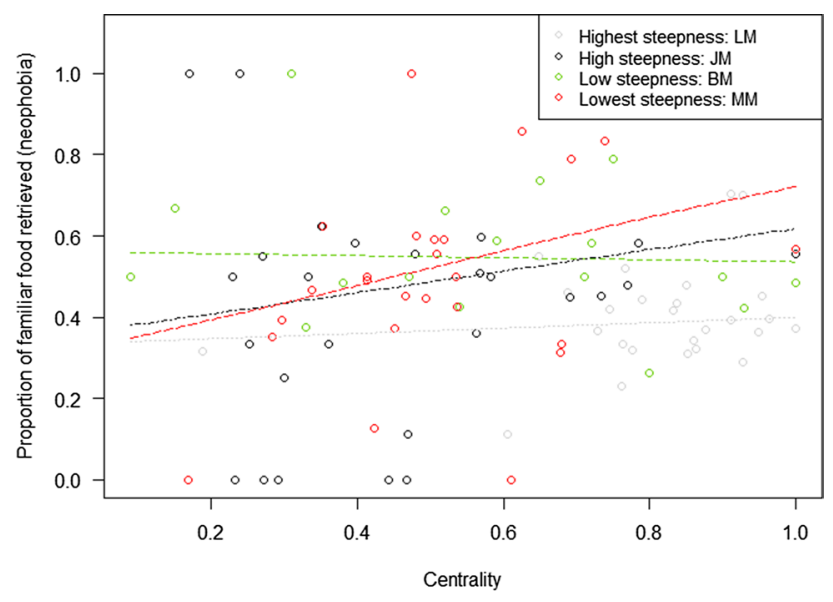

Figure 4. Mean proportion of familiar food retrieved by the study subjects in the social tolerance task (out of the total food retrieved by the subjects, as a measure of neophobia), as a function of their steepness and Eigenvector centrality (model 3). Circles represent the study subjects and are jittered to avoid overlap. Therefore, more neophobic subjects are those depicted in the upper part of the graph. The dashed lines depict the models, which have been back-transformed from the log-odds ratio scale and contain standardized controls.

populations and not necessarily correlating with each other ${ }^{63,73,74}$. Long-tailed macaques (LM), for instance, are usually considered a moderately despotic species in the literature ${ }^{4,5}$, but in this study their dominance steepness was higher than our study group of Japanese macaques (JM), while their tolerance over food was higher than that of the other three species.

Demographic characteristics of the study groups do not seem to explain these results: Although LM had the highest proportion of juveniles and subadults in the group, which could explain the unexpected high tolerance over food, the results did not change when only analysing the proportion of adults retrieving food (see Supplementary Materials). Alternatively, the specific socio-ecological factors experienced may determine whether despotic tendencies and/or other aspects of dominance style (e.g. tolerance over food) really emerge in a given group. Even the degree of cohabitation with humans and experience in urban habitats may affect the way individuals behave (see e.g. ${ }^{73}$ ). Although all the study groups were used to humans and partially food-provisioned, the group of LM was living in a more urban area, which might have affected their unexpectedly high tolerance over food (e.g. by providing easier access to food sources, and thus reducing competition over food). Whether this is the case, however, remains at the moment pure speculation. Moreover, one should note that previous studies assessing dominance styles in macaques found a high consistency within species, even if they were tested in very different settings (e.g. captive and wild ones; $\mathrm{se}^{4,75}$ ). Finally, it is interesting to note the larger variation in the proportion of food retrievers in LM, as compared to the other species (Fig. 2). In some sessions, only few LM individuals were present (while the other group members were visible just outside the testing arena). In other sessions, however, almost all the group members were simultaneously inside the testing arena. However, there was no apparent reason for this variation, which was also not linked to the specific identity of the individuals in the testing arena (e.g. higher-ranking individuals could be completely alone in some sessions, or surrounded by many other group members in others).

In our study, the effect of Eigenvector centrality on neophobia also varied across individuals and species, based on their dominance steepness. When re-analysing the data on neophobia by only including the first 6 sessions (to ensure that subjects were not yet habituated to the "novel" stimuli; see Supplementary Materials), the results did not change. In particular, our study showed that less central individuals were less neophobic, but this pattern was only evident in less despotic species. This seems to contrast with our prediction, that the tendency to overcome neophobia is a response of individuals who would otherwise have little access to food to increase food intake. If this was true, neophobia should decrease in less central individuals, as we showed, but mostly in despotic species, as competition over food should be fiercer in these species (see Prediction 3). However, note that, in this study, more despotic species were also the ones with a higher proportion of individuals retrieving food. Therefore, it is possible that, in the presence of novel food, less central individuals more often had to rely on novel food sources to get a share of resources, but only in the groups which showed little tolerance over food (regardless of their dominance steepness). In this view, our Prediction 3 appears confirmed, in that less central individuals more strongly relied on novel food when access to food was more uneven across group members (i.e., surprisingly, in less despotic species). Therefore, although less central individuals might not have a real preference for novelty, specific patterns of tolerance over food would foster them to use alternative retrieval strategies, as they might otherwise have little opportunities to access food.

Our findings can also be explained by the fact that little neophobia may provide different benefits to individuals in different species. In more despotic species, like JM, females inherit their maternal rank, so there may be little incentive for them to be attracted by novelty ${ }^{76}$. However, reduced neophobia in a feeding context may correlate with other traits (e.g. general extraversion, boldness) allowing females in other species to attain other 
benefits, like higher rank. Therefore, in less despotic species, individuals may more likely overcome neophobia, as this might provide higher benefits.

In the future, these hypotheses should be contrasted to understand whether differences in neophobia are better explained by inter- and intra-specific differences in access to food or personality traits that might favour rank advancement in species with little maternal rank inheritance. Furthermore, future studies should better disentangle the role played by the presence of more dominant individuals on subjects' performance in neophobia tasks. In this study, we focused on individuals' ability to overcome neophobia in order to maximize food income. In the future, however, it could be interesting to compare this ability to individual preference for novel food in the absence of contest competition (e.g. by comparing individual preferences for novel food when individuals are tested alone or in group). Moreover, future studies should ideally include a larger variety of novel stimuli. Although in this study we used two different conditions and two different novel stimuli per condition, several species are known to strongly vary in their reactions to different novel stimuli. Thus, using a wider range of stimuli would allow a test of the consistency of our findings ${ }^{62}$. This is especially important if one considers that novelty is after all a matter of degree: no stimulus can be completely novel, as it necessarily shares features with other already familiar stimuli. Finally, differences across study groups might also depend on the different experience of the study groups in urban habitats, as neophobia is known to decrease in urban environments (see ${ }^{73}$ ).

The results of our study confirm that, beyond dominance rank, other individual characteristics like social integration (measured as Eigenvector centrality in the social network) may have a crucial effect on individuals' ability to access resources. Although the role of social integration in access to food has rarely been investigated, these results are in line with a recent study on captive Guinea baboons (Papio papio ${ }^{22}$ ) and support a clear link between social integration and fitness in both human ${ }^{77,78}$ and non-human primates ${ }^{50-52,54,55}$.

Overall, our study revealed both inter- and intra-specific differences in individuals' access to food, which partially reflected the dominance styles of the species examined, and in unexpected ways. In the future, studies will need to directly assess other social aspects of the study groups that might be linked to differences in dominance styles (e.g. agonistic interactions, conflict management patterns, nepotism, availability of social partners, tolerance over food), and the socio-ecological factors that might explain these differences, both across and within species. Further studies should also investigate the role of Eigenvector centrality in access to food, to better understand the multiple effects that sociality may have on fitness, and better disentangle possible differences between male and female behaviour, as differences in dominance style should mainly affect females ${ }^{4,5}$.

Received: 8 July 2020; Accepted: 3 December 2020

Published online: 16 December 2020

\section{References}

1. de Waal, F. B. M. Dominance "style" and primate social organization in Comparative socioecology (eds. Standen, V. \& Foley, R. A.). 243-264 (Blackwell, London, 1989).

2. Flack, J. C. \& de Waal, F. B. M. Dominance style, social power, and conflict in Macaque societies: a model for the study of social organization (eds. Thierry, B., Singh, M. \& Kaumanns, W.) 157-182 (Cambridge University Press, Cambridge, 2004).

3. Thierry, B., Singh, M. \& Kaumanns, W. (eds). Macaque Societies: A Model for the Study of Social Organization (Cambridge University Press, Cambridge, 2004).

4. Thierry, B. Covariation of conflict management patterns across macaque species in Natural conflict resolution (eds. Aureli, F. \& de Waal, F.) 106-128 (University of California Press, Cambridge, 2000).

5. Thierry, B. Unity in diversity: lessons from macaque societies. Evol. Anthropol. Issues News Rev. 16, 224-238 (2007).

6. Butovskaya, M. Social space and degrees of freedom in Macaque Societies: A Model for the Study of Social Organization (eds. Thierry, B., Singh, M. \& Kaumanns, W.) 182-185 (Cambridge University Press, Cambridge, 2004).

7. Cooper, M. A. \& Bernstein, I. S. Evaluating dominance styles in Assamese and rhesus macaques. Int. J. Primatol. 29, 225-243 (2008).

8. Duboscq, J. et al. Social tolerance in wild female crested macaques (Macaca nigra) in Tangkoko-Batuangus Nature Reserve, Sulawesi, Indonesia. Am. J. Primatol. 75, 361-375 (2013).

9. Thierry, B. Feedback loop between kinship and dominance: the macaque model. J. Theor. Biol. 145, 511-521 (1990).

10. Hare, B., Melis, A. P., Woods, V., Hastings, S. \& Wrangham, R. Tolerance allows bonobos to outperform chimpanzees on a cooperative task. Curr. Biol. 17, 619-623 (2007).

11. Melis, A. P., Hare, B. \& Tomasello, M. Engineering cooperation in chimpanzees: tolerance constraints on cooperation. Anim. Behav. $72,275-286$ (2006).

12. Altmann, S. A. Foraging for Survival: Yearling Baboons in Africa (University of Chicago Press, Chicago, 1998).

13. Hohmann, G., Robbins, M. M. \& Boesch C (eds). Feeding Ecology in Apes and Other Primates (Cambridge University Press, Cambridge, 2006).

14. Clutton-Brock, T. H., Albon, S. D. \& Guiness, F. E. Maternal dominance, breeding success and birth sex ratios in red deer. Nature 308, 58-60 (1984).

15. Dunbar, R. M. \& Dunbar, P. Dominance and reproductive success among female gelada baboons. Nature 266, 351-352 (1977).

16. Hohmann, G., Robbins, M. M. \& Boesch, C. (eds). Feeding ecology in apes and other primates (Cambridge University Press, Cambridge, 2006).

17. Janson, C. H. \& van Schaik, C. P. Recognizing the many faces of primate food competition: methods. Behav. 105, 165-186 (1988).

18. King, A. J., Douglas, C. M., Huchard, E., Isaac, N. J. \& Cowlishaw, G. Dominance and affiliation mediate despotism in a social primate. Curr. Biol. 18, 1833-1838 (2008).

19. Romero, T. \& Castellanos, M. A. Dominance relationships among male hamadryas baboons (Papio hamadryas). J. Ethol. 28, 113-121 (2010).

20. Wong, M. Y. L., Munday, P. L., Buston, P. M. \& Jones, G. P. Fasting or feasting in a fish social hierarchy. Curr. Biol. 18, 372-373 (2008).

21. Farine, D. R. \& Whitehead, H. Constructing, conducting, and interpreting animal social network analysis. J. Anim. Ecol. 84, $1144-1163(2015)$

22. Dell'Anna, F., Llorente, M., Schloegl, B., von Fersen, L. \& Amici F. Individual and food characteristics affect food retrieval in captive Guinea baboons (Papio papio). Am. J. Primatol., 82 (2019). 
23. de Waal, F. B. M. Good natured: the origins of right and wrong in humans and other animals (Harvard University Press, London, 1996).

24. de Waal, F. B. M. Joint ventures require joint payoffs: fairness among primates. Soc. Res. 73, 349-364 (2006).

25. Brosnan, S. F. Nonhuman species' reactions to inequity and their implications for fairness. J. Soc. Just. 19, 153-185 (2006).

26. Amici, F., Call, J. \& Aureli, F. Aversion to violation of expectations of food distribution: the role of social tolerance and relative dominance in seven primate species. Behav. 149, 345-368 (2012).

27. Mitchell, C. L., Boinski, S. \& van Schaik, C. P. Competitive regimes and female bonding in two species of squirrel monkeys (Saimiri oerstedi and S. sciureus). Behav. Ecol. Sociobiol. 28, 55-60 (1991).

28. Barton, R. A., Byrne, R. W. \& Whiten, A. Ecology, feeding competition and social structure in baboons. Behav. Ecol. Sociobiol. 38, $321-329$ (1996).

29. Greenberg, R. \& Mettke-Hofmann, C. Ecological aspects of neophobia and neophilia in birds. Curr. Ornithol. 16, 119-178 (2001).

30. Amici, F., Lehmann, J., Widdig, A. \& Majolo, B. A meta-analysis of inter-individual differences in innovation. Anim. Behav. 155, $257-268$ (2019).

31. Greenberg, R. The role of neophobia and neophilia in the development of innovative behaviour of birds in Animal innovation (eds. Greenberg, R., Reader, S. M. \& Laland, K. N.) 175-196 (Oxford University Press, Oxford, 2003).

32. Greenberg, R. \& Mettke-Hofmann, C. Ecological aspects of neophobia and neophilia in birds in Current ornithology (eds. Volan, V. \& Thompson, C. F.) 119-178 (Springer, London, 2001).

33. Reader, S.M. \& Laland, K. N. Animal innovation (Oxford University Press, Oxford, 2003).

34. Sol, D. The evolution of innovativeness: exaptation or specialized adaptation? In Animal creativity and innovation (eds. Kaufman, A. B. \& Kaufman, J. C.) (Academic Press, London, 2015).

35. Fragaszy, D. M., Visalberghi, E. \& Galloway, A. T. Infant tufted capuchin monkeys' behaviour with novel foods: opportunism, not selectivity. Anim. Behav. 53, 1337-1343 (1997).

36. Freeland, W. J. \& Janzen, D. H. Strategies in herbivory by mammals: the role of plant secondary compounds. Am. Nat. 108, 269-289 (1974).

37. Glander, K. E. The impact of plant secondary compounds on primate feeding behavior. Yearb. Phys. Anthropol. 25, 1-18 (1982).

38. Milton, K. Diet and primate evolution. Sci. Am. 269, 70-77 (1993).

39. Rozin, P. The significance of learning mechanisms in food selection: some biology, psychology, and sociology of science in Learning mechanisms in food selection (eds. Barker, L. M., Best, M. R. \& Domjan, M.) 557-592 (Baylor University Press, London, 1977).

40. Ueno, A. \& Matsuzawa, T. Response to novel food in infant chimpanzees. Do infants refer to mothers before ingesting food on their own? Behav. Processes 68, 85-90 (2005).

41. Visalberghi, E., Myowa-Yamakoshi, M., Hirata, S. \& Matsuzawa, T. Responses to novel foods in captive chimpanzees. Zoo Biol. 21, $539-548$ (2002).

42. Visalberghi, E., Janson, C. H. \& Agostini, I. Response towards novel foods and novel objects in wild tufted capuchins (Cebus apella). Int. J. Primatol. 24, 653-675 (2003).

43. Ellis, L. Dominance and reproductive success among nonhuman animals: a cross-species comparison. Ethol. Sociobiol. 16, 257-333 (1995).

44. Hegner, R. E. Dominance and anti-predator behaviour in blue tits (Parus caeruleus). Anim. Behav. 33, 762-768 (1985).

45. Greenberg-Cohen, D., Alkon, P. U. \& Yom-Tov, Y. A linear dominance hierarchy in female Nubian ibex. Ethol. 210-220 (1994).

46. Lahti, K. Social dominance and survival in flocking passerine birds: a review with an emphasis on the willow tit Parus montanus. Ornis Fennica. 75, 1-17 (1998).

47. Laland, K. N. \& Reader, S. M. Foraging innovation in the guppy. Anim. Behav. 57, 331-340 (1999).

48. Wolf, M., van Doorn, G. S., Leimar, O. \& Weissing, F. J. Life-history trade-offs favour the evolution of animal personalities. Nature 447, 581-584 (2007).

49. Cameron, E. Z., Setsaas, T. H. \& Linklater, W. L. Social bonds between unrelated females increase reproductive success in feral horses. Proc. Natl Acad. Sci. USA 106, 13850-13853 (2009).

50. Schülke, O., Bhagavatula, J., Vigilant, L. \& Ostner, J. Social bonds enhance reproductive success in male macaques. Curr. Biol. 20, 2207-2210(2010).

51. Silk, J. B., Alberts, S. C. \& Altmann, J. Social bonds of female baboons enhance infant survival. Science 302, 1231-1234 (2003).

52. Silk, J. B. et al. The benefits of social capital: close social bonds among female baboons enhance offspring survival. Proc. R. Soc. $B$ 276, 3099-3104 (2009).

53. Stanton, M. A. \& Mann, J. Early social networks predict survival in wild bottlenose dolphins. PLoS ONE 7, e47508 (2012).

54. Silk, J. B. et al. Strong and consistent social bonds enhance the longevity of female baboons. Curr. Biol. 20, 1359-1361 (2010).

55. Archie, E. A., Tung, J., Clark, M., Altmann, J. \& Alberts, S. C. Social affiliation matters: both same-sex and opposite-sex relationships predict survival in wild female baboons. Proc. R. Soc. B 281, 20141261 (2014).

56. Farine, D. R. A guide to null models for animal social network analysis. Methods Ecol. Evol. 8, 1309-1320 (2017).

57. Neumann, C. et al. Assessing dominance hierarchies: validation and advantages of progressive evaluation with Elo-rating. Anim. Behav. 82, 911-921 (2011).

58. Neumann, C. \& Kulik, L. Animal dominance hierarchies by Elo Rating. R package version 0.46 .11 (2020).

59. Oksanen, J. et al. vegan: community ecology package. R package version 2.5-3 (2018).

60. Farine, D. R. asnipe: animal social network inference and permutations for ecologists. R package version 1.1.10 (2018).

61. Csardi, G. \& Nepusz, T. The igraph software package for complex network research. Int. J. Complex Systems 1695 (2006).

62. Greggor, A. L., Thornton, A. \& Clayton, N. S. Neophobia is not only avoidance: improving neophobia tests by combining cognition and ecology. Curr. Opin. Behav. Sci. 6, 82-89 (2015).

63. de Vries, H., Stevens, J. M. G. \& Vervaecke, H. Measuring and testing the steepness of dominance hierarchies. Anim. Behav. 71, 585-592 (2006).

64. Leiva, D. \& de Vries, H. steepness: testing steepness of dominance hierarchies. R package version 0.2-2 (2014).

65. R Core Team. R: A language and environment for statistical computing. Wien, Austria (2020).

66. Balasubramaniam, K. N. et al. Hierarchical steepness and phylogenetic models: phylogenetic signals in Macaca. Anim. Behav. 83, $1207-1218(2012)$.

67. Klass, K. \& Cords, M. Effect of unknown relationships on linearity, steepness and rank ordering of dominance hierarchies: simulation studies based on data from wild monkeys. Behav. Proc. 88, 168-176 (2011).

68. Baayen, R. H., Davidson, D. J. \& Bates, D. M. Mixed-effects modeling with crossed random effects for subjects and items. J. Mem. Lang. 59, 390-412 (2008).

69. Brooks, M. E. et al. glmmTMB balances speed and flexibility among packages for zero-inflated generalized linear mixed modeling. R J. 9, 378-400 (2017).

70. Dobson, A., Zidek, J., Lindsey, J., Zidek, J. \& Lindsey, J. An introduction to Generalized Linear Models (Chapman and Hall/CRC, London, 2001)

71. Barr, D. J., Levy, R., Scheepers, C. \& Tily, H. J. Random effects structure for confirmatory hypothesis testing: keep it maximal. J. Mem. Lang. 68, 255-278 (2013).

72. Field, A. Discovering statistics using SPSS (SAGE Publications Ltd, Berlin, 2005).

73. Barrett, L. P., Stanton, L. A. \& Benson-Amram, S. The cognition of 'nuisance' species. Anim. Behav. 147, 167-177 (2019). 
74. de Waal, F. B. \& Luttrell, L. M. Toward a comparative socioecology of the genus Macaca: different dominance styles in rhesus and stumptail monkeys. Am. J. Primatol. 19, 83-109 (1989).

75. Berman, C. M. \& Thierry, B. Variation in kin bias: species differences and time constraints in macaques. Behav. 147, 1863-1887 (2010).

76. Nakamichi, M. \& Yamada, K. Lifetime social development in female Japanese macaques in The Japanese macaques (eds. Nakagawa, N., Nakamichi, M. \& Sugiura, H.) 241-270 (Springer, London, 2010).

77. Holt-Lunstad, J., Smith, T. B. \& Layton, J. B. Social relationships and mortality risk: a meta-analytic review. PLoS Med. 7, e1000316 (2010).

78. Smith, K. P. \& Christakis, N. A. Social networks and health. Annu. Rev. Sociol. 34, 405-429 (2008).

\section{Acknowledgements}

We are grateful to the Kementarian Negara Riset dan Teknologi Republik Indonesia (RISTEK) and to the Taman Nasional Bantimurung-Bulusaraung (TNBABUL) for their permission to conduct research in the National Park on Sulawesi. We also thank the cooperative research program of Kyoto University's Wildlife Research Center and the city of Kushima's Agency for Cultural Affairs for permissions to conduct this research in Japan, and Takafumi Suzumura and Zhihong Xu for help with logistics in the field. Furthermore, we are grateful to Eric Shaw and Tessa Feeney for facilitating access to the Barbary macaques in Gibraltar, and to Prof. Shahrul for facilitating access to the long-tailed macaques in Malaysia. Finally, we are especially grateful to Filippo Aureli for generous feedback on a previous version of the manuscript. This project was supported by a German Research Foundation (DFG) research Grant to FA (AM 409/4-1), and by the University of Leipzig, Germany. We acknowledge support from the Max Planck Society for the opportunity to publish Open Access.

\section{Author contributions}

F.A. designed and coordinated the study, with extensive feedback from B.M. and A.W. V.B.F., A.C.N., A.L.C., K.K. and A.S.H. collected the data, with extensive help from A.J.J.M., R.I.M. and P.O.N. F.A. analyzed the data, with feedback from A.J.J.M., B.M. and A.W. F.A wrote the paper, with extensive feedback from A.J.J.M., B.M., A.W. and all the other co-authors.

\section{Funding}

Open Access funding enabled and organized by Projekt DEAL.

\section{Competing interests}

The authors declare no competing interests.

\section{Additional information}

Supplementary Information The online version contains supplementary material available at https://doi. org/10.1038/s41598-020-79246-6.

Correspondence and requests for materials should be addressed to F.A.

Reprints and permissions information is available at www.nature.com/reprints.

Publisher's note Springer Nature remains neutral with regard to jurisdictional claims in published maps and institutional affiliations.

Open Access This article is licensed under a Creative Commons Attribution 4.0 International License, whi..ch permits use, sharing, adaptation, distribution and reproduction in any medium or format, as long as you give appropriate credit to the original author(s) and the source, provide a link to the Creative Commons licence, and indicate if changes were made. The images or other third party material in this article are included in the article's Creative Commons licence, unless indicated otherwise in a credit line to the material. If material is not included in the article's Creative Commons licence and your intended use is not permitted by statutory regulation or exceeds the permitted use, you will need to obtain permission directly from the copyright holder. To view a copy of this licence, visit http://creativecommons.org/licenses/by/4.0/.

(c) The Author(s) 2020 